\title{
Research with Marginalized Communities: Challenges to Continuity During the COVID-19 Pandemic
}

\author{
Jae M. Sevelius ${ }^{1}$. Luis Gutierrez-Mock ${ }^{1}$ - Sophia Zamudio-Haas ${ }^{1}$ - Breonna McCree ${ }^{1}$ Azize Ngo ${ }^{1}$. Akira Jackson ${ }^{1}$. \\ Carla Clynes $^{1} \cdot$ Luz Venegas $^{1} \cdot$ Arianna Salinas $^{1} \cdot$ Cinthya Herrera $^{1} \cdot$ Ellen Stein $^{1} \cdot$ Don Operario $^{2} \cdot$ Kristi Gamarel $^{3}$
}

Published online: 16 May 2020

(c) Springer Science+Business Media, LLC, part of Springer Nature 2020

Marginalized communities are those excluded from mainstream social, economic, educational, and/or cultural life. Examples of marginalized populations include, but are not limited to, groups excluded due to race, gender identity, sexual orientation, age, physical ability, language, and/or immigration status. Marginalization occurs due to unequal power relationships between social groups [1].

Conducting research in partnership with marginalized groups has inherent challenges. Traditional academic research can reenact and reinforce stigma and power imbalances, even if inadvertently, and marginalization itself can limit the ability of certain groups to participate meaningfully in research [2,3]. The recent outbreak of SARS-CoV-2, the virus that causes COVID-19, has caused massive disruptions in the lives of people all over the globe, and has brought research focused on addressing health inequities, such as HIV, largely to a halt.

Further, the pandemic and the related shutdown of many systems, including community-based clinics, resources, and support services, is further exacerbating the experience of marginalization for many communities [4]. In transgender and gender diverse communities within which our team works, we are seeing this play out in our reduced ability to sustain connection with our research participants and maintain continuity of our research efforts.

Jae M. Sevelius

j.sevelius@ucsf.edu

1 Center of Excellence for Transgender Health, Department of Medicine, University of California, San Francisco, San Francisco, CA, USA

2 School of Public Health, Brown University, Providence, RI, USA

3 School of Public Health, University of Michigan, Ann Arbor, MI, USA

\section{Technological Challenges to Conducting Research Online with Marginalized Communities}

Due to longstanding political, economic, educational, and employment marginalization, many in our communities do not have access to the technology and/or technological skills needed to be able to participate in online research [5]. It has previously been documented that online research and eHealth approaches are less likely to reach more marginalized populations, such as people of color, homeless people, and LGBTQ youth [6, 7].

Due to economic marginalization, many in our communities do not have consistent access to smartphones or computers [8]. They may have their phone service or internet access repeatedly interrupted due to inability to pay bills. Reaching marginalized people via the internet, email, or social media is often intermittent at best, impossible at worst.

Even among those who may have access to the internet and a smartphone or computer, due to educational marginalization, many in our communities do not have the technological skills needed to navigate online studies, sign electronic documents, or read and respond to self-administered surveys [7]. As we attempt to reconvene our peer-delivered intervention groups and individual sessions, we are finding that our participants have very little, if any, familiarity with applications such as Zoom, and require extensive technical assistance to install, set up, register for, and use these programs. Video conferencing applications they may be familiar with, such as Facebook Messenger, have only recently been made allowable platforms for telehealth purposes due to security issues [9]. 


\section{Challenges to Reimbursing Participants from Economically Marginalized Communities}

The immediate financial support that research incentives provide are often extremely helpful for people in our communities. Due to employment marginalization, many of our participants are not eligible for programs such as unemployment insurance benefits or the new Pandemic Unemployment Assistance program. Competing priorities, such as food insecurity, that have always been a barrier to conducting research with marginalized populations, are magnified by the current disruption to usual support services [8].

Even if we are able to reach participants and complete research activities with them online, reimbursing them for their participation is a serious barrier. Institutional barriers prevent us from paying our participants via Venmo or PayPal. Further, many participants in our studies do not have bank accounts, and thus cannot set up accounts with PayPal or Venmo for receiving funds. Further, using these apps requires someone from the research team to transfer personal funds in order to work around institutional barriers to using these solutions. While applications like CashApp do not require the recipient to have a bank account, the lack of technological skills can prevent people from registering.

Electronic gift cards, which have become popularized in online research due to their convenience for researchers [10], are often not useful to our participants. Electronic gift cards do not permit our participants to access the resources they may need most, such as food or more immediate survival needs from vendors that require cash. Many people do not have a safe place to receive packages from online vendors, such as Amazon. Our community members, many of whom live in shelters, single resident occupancy hotels (SROs), and other congregate living situations [11], commonly experience theft of their mail and belongings.

\section{Challenges to Safety}

Marginalized communities are more susceptible to COVID-19 for multiple reasons [12]. Many of our participants are living in conditions where they are unable to follow COVID-19 public health and safety recommendations during this pandemic. Community members who live in shelters and SROs report living in unclean facilities, not having access to cleaning supplies, and not being able to properly physically distance from their neighbors. Many
SROs have shared bathrooms, with multiple doors to touch between one's own room and the bathroom, and some personal rooms do not have sinks for handwashing. In addition to jeopardizing their physical health, these shared living situations often make participating in research nearly impossible, since there is limited privacy in which to respond to sensitive research questions [13].

Those in our communities who engage in survival sex work are continuing to do so out of necessity, even as the inherent dangers in this work are increasing [14]. Many people in our communities report that sex work is currently a booming business, as clients experiencing stress and social isolation seek out services. Still, there have been reports of sex work clients who are desperate for money physically attacking and robbing sex workers.

Finally, the mental health impact of this pandemic and its effects are likely to disproportionately affect marginalized communities [15]. Among our transgender and gender diverse staff and participants, delays in gender-affirming treatment, such as hormone injections and surgeries, due to the shutdown of clinics and delays in "elective" surgeries, can cause serious mental health issues, including depression, anxiety, and suicidality [16]. Further, social isolation due to physical distancing mandates can make it even more difficult to cope [17]. Many people in our communities rely on regular in-person support groups to cope with ongoing mental health issues and are unable to access online resources for the reasons outlined above.

\section{Possible Ways Forward}

While we at the Center of Excellence for Transgender Health are still experimenting with ways of reaching, engaging, and supporting marginalized research participants, we have been exploring possible ways forward.

\section{Collaborations with Community-Based Agencies Providing Emergency Services}

Some agencies and advocacy groups are distributing food and other emergency supplies safely within the community. By collaborating with these agencies and groups, we may be able to reconnect with our participants, or get reimbursements for participation to people we would not otherwise be able to connect with in-person. These collaborations rely upon existing relationships with our community partners and can be time intensive [4]. This also requires our team to consistently identify and track resources and determine how to communicate emergent information efficiently and effectively to participants. 


\section{Interviewer Administered Surveys via Phone Calls}

For participants who cannot take surveys online due to lack of access to a computer or the internet, or due to literacy issues, staff may call participants and administer the survey over the phone. This takes a great deal of staff time, which can be difficult in terms of staff energy and emotional resources [18]. In addition, staff themselves are often not experts with the technology and can similarly struggle with online surveys. It also takes additional time to train staff to administer surveys to participants, as this is a specific skill that takes time to develop.

\section{Telehealth Delivery of Interventions}

Interruptions to the delivery of interventions in the context of a clinical trial can be especially difficult. While adapting the intervention to an online version is critical to maintaining continuity of the research, doing so without time to undertake proper adaptation and training procedures can create unexpected risks and burdens [7]. Using a secure online platform like Zoom often requires technical assistance, as previously stated, and questions about privacy often arise when participants live in shared spaces [19].

\section{Community Capacity Building to Use Technology}

We have successfully conducted some peer-led groups online with our participants via Zoom. In some cases, this has required extensive capacity building, even within our own team, to use the technology effectively. Supplemental funding to research projects could assist with conducting more extensive capacity building within our communities, which would also allow marginalized people to access other resources, such as informational webinars, that they may not have previously had the skills to access.

\section{Resource Mapping, Dissemination, and Referrals}

As communities and local governments mobilize to create resources for vulnerable communities, the need for assistance to successfully connect people to these resources has become apparent. In our transgender and gender diverse communities, we have identified the need to collect and map these resources, gather them into an accessible and updatable format, and disseminate them among our participants as well as provide direct and tailored referrals. To this end, the UCSF Center of Excellence for Transgender Health, the UCSF Center for Sexual and Gender Minority Health, and the UCSF LGBT Resource Center teamed up to present a Grand Rounds webinar on COVID-19 information and resources specific to our communities.

\section{Trauma-Informed Peer Support}

Our front-line staff are interacting directly with people who are in crisis due to exacerbated marginalization as a result of the pandemic. As a result, we have identified the need for additional and ongoing trainings on the provision of traumainformed peer support for our communities, especially frontline staff [18].

\section{Instrumental Support}

Our front-line and supervisory staff are hyper aware of the immense needs in our communities and are making every effort to help meet those needs. To that end, we are helping to coordinate food bank pickups, no-contact grocery drop-off to participants without transportation, delivering condoms and lube to participant residences, coordinating with our collaborative partners to help support the many needs of our communities and assisting our participants with applications to relevant funding sources. We are also raising funds to directly provide monetary support to trans community members who are struggling to pay their bills, prioritizing our monolingual Spanish-speaking, undocumented and/or sex-working community members. Further, optimizing our ability to continue our research activities can help to supplement income for our communities through reimbursements.

\section{Conclusion}

In summary, there are new and intensified barriers to maintaining research continuity with marginalized populations due to the global COVID-19 pandemic. It is critical that research teams not only get creative about ways of reaching, engaging, and reimbursing our participants during this crisis, but also find ways to come together with communities to create, identify, and disseminate resources to those most in need. In order to do this, we must receive robust support from our institutions and funders to meet the needs of our participants, especially those from marginalized communities.

Acknowledgements Funding for the research described in this article is provided by the National Institutes of Health (R01MH115765, MPIs Gamarel, Operario, Sevelius, and R01MH106373, PI Sevelius) and the California HIV/AIDS Research Program (PR15-SF-007, PI Sevelius).

\section{References}

1. Baah FO, Teitelman AM, Riegel B. Marginalization: conceptualizing patient vulnerabilities in the framework of social 
determinants of health-An integrative review. Nursing Inquiry. 2019;26(1):e12268.

2. Wallerstein N, Muhammad M, Sanchez-Youngman S, Rodriguez Espinosa P, Avila M, Baker EA, et al. Power dynamics in community-based participatory research: a multiple-case study analysis of partnering contexts, histories, and practices. Health Educ. Behav. 2019;46(1):19S-32S.

3. Parson L. Considering positionality: the ethics of conducting research with marginalized groups. In: Strunk KK, Locke LA, editors. Research methods for social justice and equity in education. Cham: Springer International Publishing; 2019. p. 15-32.

4. Operario D, King EJ, Gamarel KE. Prioritizing community partners and community HIV workers in the COVID-19 pandemic. AIDS Behav. 2020. https://doi.org/10.1007/s10461-020-02896-0.

5. Marhefka SL, Lockhart E, Turner D, Wang W, Dolcini MM, Baldwin JA, et al. Social determinants of potential eHealth engagement among people living with HIV receiving ryan white case management: health equity implications from project TECH. AIDS Behav. 2020;24(5):1463-75.

6. McInroy LB. Pitfalls, potentials, and ethics of online survey research: LGBTQ and other marginalized and hard-to-access youths. Soc Work Res. 2016;40(2):83-94.

7. Schueller SM, Hunter JF, Figueroa C, Aguilera A. Use of digital mental health for marginalized and underserved populations. Curr Treat Opt Psychiatry. 2019;6(3):243-55.

8. Reback CJ, Ferlito D, Kisler KA, Fletcher JB. Recruiting, linking, and retaining high-risk transgender women into HIV prevention and care services: an overview of barriers, strategies, and lessons learned. Int J Transgender. 2015;16(4):209-21.

9. Services USDoHH. Notification of enforcement discretion for telehealth remote communications during the COVID-19 nationwide public health emergency. Health Information Privacy. 2020, 30 March. https://www.hhs.gov/hipaa/for-professionals/special-topic s/emergency-preparedness/notification-enforcement-discretion -telehealth/index.html.

10. Saberi P. Research in the time of coronavirus: continuing ongoing studies in the midst of the COVID-19 pandemic. AIDS Behav. 2020. https://doi.org/10.1007/s10461-020-02868-4.

11. Schick V, Witte L, Misedah L, Benedict W, Falk K, Brown C, et al. Exploring differences in the lives and well-being of sexual and gender minority adults experiencing homelessness relative to their cisgender heterosexual counterparts. Health Equity. 2019;3(1):68-72.

12. Ahmed F, Ahmed N, Pissarides C, Stiglitz J. Why inequality could spread COVID-19. Lancet Public Health. 2020;5:e240.

13. Green SM, Lockhart E, Marhefka SL. Advantages and disadvantages for receiving Internet-based HIV/AIDS interventions at home or at community-based organizations. AIDS Care. 2015;27(10):1304-8.

14. UNAIDS, Projects GNoSW. Sex workers must not be left behind in the response to COVID-19. Joint Statement. 2020; 8 April. https://www.unaids.org/en/resources/presscentre/pressreleaseand statementarchive/2020/april/20200408_sex-workers-covid-19.

15. Galea S, Merchant RM, Lurie N. The mental health consequences of COVID-19 and physical distancing: the need for prevention and early intervention. JAMA Int Med. 2020. https://doi.org/10.1001/ jamainternmed.2020.1562.

16. Bränström R, Pachankis JE. Reduction in mental health treatment utilization among transgender individuals after gender-affirming surgeries: a total population study. Am J Psychiatry. 2019. https ://doi.org/10.1176/appi.ajp.2019.19010080.

17. Marziali ME, Card KG, McLinden T, Wang L, Trigg J, Hogg RS. Physical distancing in COVID-19 may exacerbate experiences of social isolation among people living with HIV. AIDS Behav. 2020. https://doi.org/10.1007/s10461-020-02872-8.

18. Smith AM, Hamilton AB, Loeb T, Pemberton J, Wyatt GE. Reactions of novice interviewers conducting trauma research with marginalized communities: a qualitative analysis. J Interperson Violence. 2019. https://doi.org/10.1177/0886260519889925.

19. Marhefka S, Lockhart E, Turner D. Achieve research continuity during social distancing by rapidly implementing individual and group videoconferencing with participants: key considerations, best practices, and protocols. AIDS Behav. 2020. https://doi. org/10.1007/s10461-020-02837-x.

Publisher's Note Springer Nature remains neutral with regard to jurisdictional claims in published maps and institutional affiliations. 